\title{
Los procesos de salud-enfermedad-atención desde la perspectiva de los usuarios de una policlínica del primer nivel de atención en Montevideo, Uruguay: Análisis de trayectos terapéuticos
}

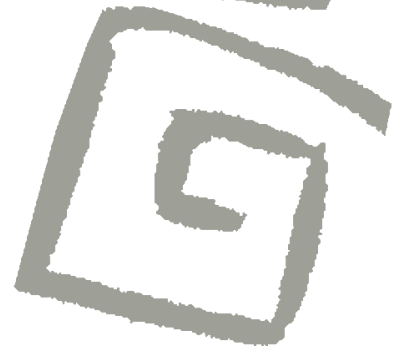

\author{
The health-disease-care process from the perspective \\ of the users of a primary care clinic in Montevideo, \\ Uruguay: An analysis of therapeutic trajectories
}

Evia Bertullo, Victoria ${ }^{1}$

${ }^{1}$ Magíster en Ciencias Humanas opción Antropología de la Cuenca del Plata. Docente, Departamento de Antropología Social, Instituto de Ciencias Antropológicas, Facultad de Humanidades y Ciencias de la Educación, Universidad de la República, Uruguay.

vevia@fhuce.edu.uy
RESUMEN Desde un abordaje etnográfico, este trabajo se propone analizar las experiencias en los procesos de salud-enfermedad-atención de usuarios de una policlínica de la Red de Atención Primaria Metropolitana de la Administración de los Servicios de Salud del Estado (ASSE) en Uruguay. El trabajo de campo se desarrolló en la zona noreste de la ciudad de Montevideo, desde julio de 2012 a setiembre de 2013, y combinó observación participante en espacios asistenciales y sociales y entrevistas a más de 20 usuarios. Mediante el análisis de trayectos terapéuticos encontramos que las personas combinan diferentes prácticas y sentidos a la hora de enfrentar sus padecimientos. El uso de los servicios de salud biomédicos es predominante en nuestro país; sin embargo, observamos que las personas integran prácticas de autoatención y, en algunos casos, el uso de sistemas de atención populares y religiosos. Se evidencia un pluralismo médico al enfrentar ciertos malestares de la vida cotidiana o experiencias de enfermedad significativas.

PALABRAS CLAVES Atención Primaria de Salud; Prestación de Atención de Salud; Antropología Médica; Uruguay.

\begin{abstract}
The aim of this paper is to analyze, using an ethnographic approach, the health-disease-care experiences of the users of a multi-specialty clinic that forms part of the Metropolitan Primary Health Care Network of Uruguay's Public Health Services. The fieldwork was carried out in the northeast of Montevideo from July 2012 to November 2013, combining participant observation in social and care spaces and interviews with more than 20 users. In our analysis of care trajectories we found that people incorporate different practices and beliefs when facing their health problems. The use of biomedical health care services is predominant in Uruguay; nevertheless, people engage in self-care practices and in some cases, in the use of folk, religious/magical or alternative remedies. Medical pluralism is therefore observed in facing certain common ailments or significant experiences of disease.
\end{abstract}

KEY WORDS Primary Health Care; Delivery of Health Care; Anthropology, Medical; Uruguay. 


\section{INTRODUCCIÓN}

Uruguay ha atravesado en los últimos años una reforma normativa del sistema sanitario que dio lugar a la concreción del Sistema Nacional Integrado de Salud (SNIS). Con la reforma del SNIS, la Atención Primaria de la Salud (APS) se definió como la estrategia prioritaria y el primer nivel de atención como la "puerta de entrada" al sistema de salud. Entendemos que, en esta coyuntura, se ponen en juego dimensiones socioculturales de los procesos de salud-enfermedad-atención en los sentidos y las prácticas tanto de usuarios como de profesionales de la salud.

En este trabajo nos propusimos indagar los sentidos y las prácticas que se ponen en juego ante diferentes padecimientos que las personas deben afrontar en la vida cotidiana y cómo se relacionan con el uso de servicios del primer nivel de atención. ¿Cuándo, por qué y para qué las personas deciden recurrir a un servicio del primer nivel de atención? ¿Hay problemas que se resuelven en el ámbito doméstico? ¿Cuándo se elige consultar al sistema de atención biomédico? ¿Las personas acceden al sistema de salud mediante el primer nivel de atención o existe otra serie de recorridos posibles? ¿Las personas consultan otros sistemas de atención aparte del biomédico? ¿Cómo se dan las articulaciones entre los diferentes niveles del sistema de salud?

Retomamos los aportes teóricos de la antropología médica crítica y proponemos una investigación desde la disciplina antropológica que aporte a la comprensión de estos procesos sociales, teniendo en cuenta las perspectivas de los actores involucrados. Para ello, abordamos los trayectos terapéuticos de usuarios de una policlínica del primer nivel de atención de la Red de Atención Primaria Metropolitana de la Administración de los Servicios de Salud del Estado (ASSE), ubicada en la zona noreste de la ciudad de Montevideo (a).

\section{Un abordaje antropológico de los procesos de salud-enfermedad-atención}

De acuerdo con la cultura de cada sociedad y su forma de organización, la humanidad ha elaborado diferentes conceptos sobre la salud, la enfermedad, las formas de alivio y las acciones de prevención y fomento de la salud. Asimismo, históricamente se han propuesto diversos modelos para comprender la noción de salud y enfermedad (1). El tratamiento antropológico de temas como la enfermedad y los sistemas médicos ha tenido distintas etapas dentro de la historia de la disciplina, diversas denominaciones, y ha sido abordado por diferentes escuelas antropológicas $(2,3)$.

La antropología médica ha hecho un esfuerzo por desnaturalizar y cuestionar las concepciones de salud y enfermedad. Ni la salud es algún tipo de estado absoluto de bienestar ni la enfermedad es un resultado directo de un patógeno o de un disturbio fisiológico. Algunos autores (4) definen la salud como el acceso a de los bienes materiales y no materiales que sostienen y promueven la vida a un alto nivel de satisfacción y su control. La salud es un concepto elástico que debe ser evaluado en un contexto sociocultural.

El carácter particular de concebir la salud, la enfermedad y el trayecto que hay entre ellas puede denominarse como proceso de salud-enfermedadatención e incluye el padecer como parte fundamental de ese trayecto (1). En la cultura moderna, los fenómenos de salud y enfermedad constituyen un subproducto de la racionalización y fragmentación de los dominios de saber, lo cual lleva a una pérdida de la totalidad de la experiencia del padecimiento en pos del privilegio de una realidad reificada de la enfermedad (5).

Si bien las interpretaciones de la patogenia y de la terapia son esencialmente variables de una sociedad a otra, de un individuo a otro, e incluso eminentemente evolutivas en una misma sociedad, dichas interpretaciones y representaciones estarían presentes en todas las sociedades.

\footnotetext{
La idea que domina con amplitud es que la causalidad (bio) médica es inmune a la representación, como si experimentásemos la dificultad de admitir que la interpretación de la enfermedad es un fenómeno social no exclusivo del especialista, sino absolutamente de todo el mundo (6 p.1)
}

Desde la antropología médica se ha considerado la perspectiva de los usuarios o pacientes desde diferentes abordajes teórico-metodológicos. Destacamos, especialmente, el análisis de los 
trayectos terapéuticos (7) o "carrera del enfermo" (8-10) transitados por los usuarios. En este tipo de abordaje se pone el foco en las construcciones del paciente sobre su experiencia y se analizan las estrategias que estos adoptan en dichos trayectos. El énfasis en las narrativas sobre el padecimiento, así como en los modelos explicativos de los pacientes, ha servido para importantes propósitos terapéuticos (11-13). Para algunos autores, el estudio de las experiencias del malestar permite abordar la subjetividad inmersa en la vida cotidiana de las personas y, a su vez, es el "lente" a través de los cuales intentan especificar las circunstancias económicas y políticas en las que transcurren las vidas de esas personas, en espacios social y materialmente definidos (7).

Puede afirmarse que la enfermedad y la atención constituyen hechos estructurales en toda sociedad y que la atención de la enfermedad expresa las características de la sociedad en la cual se desarrolla y opera.

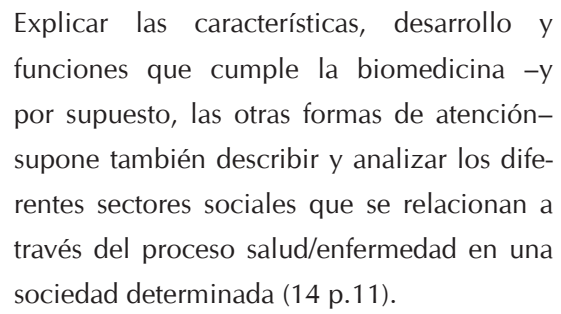

Los procesos de atención están constituidos tanto por una construcción profesional, de carácter teórico y técnico, como por una construcción social en la que se articulan procesos económicos, sociales, políticos e ideológicos (15).

En los últimos años, Uruguay ha atravesado una reforma normativa del sistema sanitario en la que se definió la APS como estrategia prioritaria y, al primer nivel de atención, como la "puerta de entrada" al sistema de salud (16). Si bien la estrategia de APS definida en la conferencia de Alma Ata de 1978 fue malinterpretada como la prestación de una mala atención a los pobres, y se consideró que se centraba exclusivamente en el primer nivel de atención, actualmente las características principales de la APS se definen como: atención centrada en las personas, integralidad e integración, continuidad asistencial y participación de los pacientes, las familias y las comunidades (17).

Al analizar la producción antropológica nacional relacionada con los procesos de salud-enfer- medad-atención, uno de los postulados propuestos por Romero en 1993, y que sigue manteniendo vigencia, es que en nuestro país la salud se encuentra en un campo relacional, "tironeado" por tendencias globales y locales, externas e internas al propio campo, con nuevos agentes de asistencia y/o curación, demandas y posicionamientos y/o cuestionamientos de tipo social y cultural que se enfrentan a la hegemonía médica (18).

La mayor parte de los trabajos sobre servicios de salud biomédicos se centran en servicios de salud del segundo y tercer nivel de atención, hospitales como el Maciel (19), el Pereira Rosell $(20,21)$, el Hospital Vilardebó $(22,23)$ o el Hospital de Tacuarembó (24), y existen escasos antecedentes de investigaciones sobre servicios de salud del primer nivel de atención. Destacamos uno de los trabajos pioneros de antropología médica en Uruguay que analizó la relación asistencial en el Centro de Salud Materno-Infantil de Ciudad Vieja de Montevideo a fines de los años ochenta y principios de los noventa. Este trabajo constató la existencia de una asimetría entre las usuarias y el personal médico y postuló la existencia de un habitus asistencial (25). Un trabajo posterior desarrollado en el Centro de Salud de Jardines del Hipódromo dio indicios de que las policlínicas del primer nivel de atención son percibidas como más cercanas geográfica y socioculturalmente que los centros de salud o los hospitales (26). Por último, otra serie de trabajos a nivel nacional se han preocupado por abordar agentes de asistencia y curación que se enfrentan a la hegemonía médica (27-30) y el surgimiento de nuevas medicinas dentro de la medicina (31).

Teniendo en cuenta el énfasis dado por la reforma sanitaria al primer nivel de atención, en este trabajo nos propusimos indagar las prácticas y los sentidos que se ponen en juego ante diferentes padecimientos que las personas deben afrontar en la vida cotidiana y cómo se relacionan con el uso de servicios del primer nivel de atención.

\section{Sector salud en Uruguay y contexto institucional del primer nivel de atención en salud}

Según datos del Instituto Nacional de Estadística, en Uruguay un 97,5\% de la población tiene derechos asistenciales en algún prestador 
de servicios de salud biomédico (32). En función de su organización institucional, el sector salud se puede descomponer en dos subsectores (33): el subsector público y el privado. El subsector público está integrado principalmente por: i) Administración de los Servicios de Salud del Estado (ASSE); ii) Sanidad de las Fuerzas Armadas; iii) Sanidad Policial; iv) Universidad de la República (Hospital de Clínicas); v) servicios de salud del Banco de Previsión Social, del Banco de Seguros del Estado y otros. El principal componente del subsector privado está conformado por las Ilamadas instituciones de asistencia médica colectiva (IAMC) y también lo integran los seguros médicos privados. El Ministerio de Salud Pública (MSP) y la Junta Nacional de Salud tienen la responsabilidad de normatizar todo lo referente al área de la salud, definir políticas, planes y programas, y fiscalizar a los aseguradores-prestadores reglamentando y vigilando el funcionamiento de las instituciones, así como el ejercicio de los profesionales de la salud (33). En cuanto a la cobertura de población, las IAMC asisten a un 58,5\% de la población, la ASSE a un $31,6 \%$ y los seguros médicos privados solo a un $2 \%$ de la población (34).

Al describir la estructura de los derechos asistenciales de los usuarios en los distintos prestadores asistenciales resulta particularmente esclarecedora la observación de Menéndez con respecto a que la enfermedad y la atención constituyen hechos estructurales en toda sociedad y que la atención de la enfermedad expresa las características de la sociedad en la cual se desarrolla y opera (14). En nuestro país se evidencia una fuerte asociación entre proveedores de salud e ingresos.

Los integrantes del quintil más pobre (primer quintil) tienen derechos de atención predominantemente en ASSE (62,2\%), y en segundo lugar en las IAMC (29,3\%), en tanto los integrantes del quinto quintil tienen derecho mayoritariamente en las IAMC (81,3\%), y en escasa medida en ASSE (5,1\%). (34 p.35)

El país ha atravesado en los últimos años una reforma normativa del sistema sanitario. Dentro de los principales lineamientos se proponen cambios en el modelo asistencial, orientados a la aplicación de una estrategia de APS con especial énfasis en el primer nivel de atención, en el modelo de financiación que se propone asegurar la equidad y la solidaridad mediante un Seguro Nacional de Salud y en un modelo de gestión democrático (35).

La reforma tiene como momento clave la aprobación de la Ley 18.211 en el Parlamento Nacional el 21 de noviembre de 2007, la cual habilita la concreción del denominado Sistema Nacional Integrado de Salud (SNIS). En el artículo 34 de la Ley (16) se define que el SNIS "tendrá como estrategia la Atención Primaria en Salud (APS) y priorizará el primer nivel de atención". En el capítulo IV de la misma Ley se proclama que el SNIS se organizará en redes por niveles de atención. Desde la bibliografía médica, los niveles de atención se definen "como una forma ordenada y estratificada de organizar los recursos para satisfacer las necesidades de la población" (36 p.12), y se distinguen tres niveles: primero, segundo y tercer nivel (36). Se entiende como primer nivel de atención al primer contacto, la puerta de entrada al sistema de salud, y se caracteriza por contar con establecimientos de baja complejidad, como consultorios, policlínicas, centros de salud, etc.; en el segundo nivel se ubican los hospitales y centros donde se prestan servicios de medicina interna, pediatría, ginecología, obstetricia, cirugía general y psiquiatría, y el tercer nivel se refiere a la atención de patologías complejas que requieren procedimientos especializados y de alta tecnología (36). Para que el proceso de atención se pueda dar de forma ininterrumpida a los usuarios, los niveles de atención deben funcionar con una adecuada referencia y contrareferencia y es fundamental la coordinación entre los diferentes niveles (37).

\section{METODOLOGÍA: ETNOGRAFÍA EN UN SERVICIO DEL PRIMER NIVEL DE ATENCIÓN EN SALUD}

La estrategia metodológica consistió en el desarrollo de una etnografía, la cual tomó como punto de partida una policlínica del primer nivel de atención de la ASSE ubicada en la zona noreste de la ciudad de Montevideo, perteneciente a la Red de Atención Primaria Metropolitana, unidad ejecutora de la ASSE que, desde marzo de 2005, organiza y gestiona el primer nivel de atención en la ciudad de Montevideo y una pequeña parte de la zona 
metropolitana. Se encuentra integrada por catorce centros de salud y sus correspondientes policlínicas y consultorios dependientes (38). Según datos oficiales, en diciembre de 2013, la ASSE tenía un total de 1.266.034 usuarios en todo el país (39), lo cual representa casi un 38\% de la población nacional.

El método etnográfico busca la inmersión en el mundo del otro (40). Para ello, tradicionalmente, la antropología ha sostenido la presencia en campo por un tiempo prolongado, compartiendo y observando tanto las actividades cotidianas como aquellas que suponen momentos significativos en una sociedad. Ese "estar allí" de forma sistemática se ha convertido en una de las técnicas distintivas del método etnográfico y se la conoce como observación participante. Esta técnica:

\footnotetext{
...consiste principalmente en dos actividades: observar sistemática y controladamente todo lo que acontece en torno al investigador $y$ participar en una o varias actividades de la población. (41 p.52)
}

El trabajo de campo se desarrolló de julio de 2012 a setiembre de 2013 y se combinó consulta bibliográfica, observación participante en espacios asistenciales y sociales, entrevistas informales a diversos usuarios y entrevistas en profundidad a usuarios y trabajadores de la salud. Se trabajó en una policlínica barrial, dependiente del Centro de Salud Jardines del Hipódromo, en la zona noreste de la ciudad de Montevideo.

Se realizó una caracterización de la población de los usuarios de la policlínica estudiada tomando como punto de partida las historias clínicas abiertas hasta agosto de 2013. Fue posible establecer que una población de 1.280 personas utiliza o utilizó la policlínica desde que comenzó a funcionar el servicio en el año 2008, en la que el 41,6\% eran hombres y el $58,4 \%$, mujeres. Mientras que la población masculina se concentraba en los niños y lactantes (0 a 9) y adolescentes (10 a 19) (ambos grupos sumaban un $65 \%$ del total de los varones), en el caso de la población femenina se destacaban especialmente las mujeres en edad fértil (15 a 44), quienes componían un 30,8\% de la población total y un $53 \%$ de las mujeres (42).

Se realizaron observaciones en sala de espera, en espacios asistenciales colectivos que funcionan en la policlínica (grupo dirigido a adultos obesos diabéticos e hipertensos denominado ODH y grupo dirigido a adolescentes denominado Espacio Adolescente), reuniones del equipo de salud, actividades de educación en salud en instituciones educativas de la zona, en actividades sociales y comunitarias vinculadas a la policlínica, y en asambleas de usuarios de la policlínica. El registro se realizó mediante cuaderno de notas in situ y a posteriori dependiendo de las características de cada instancia.

Se realizaron dos tipos de entrevistas: entrevistas informales y entrevistas en profundidad. Las entrevistas informales fueron mantenidas en el transcurso del trabajo de campo y fueron registradas mediante notas de campo in situ o a posteriori. Las entrevistas en profundidad fueron desarrolladas en un tiempo y espacio acordado para dicho fin y registradas con grabador de voz digital. Los encuentros duraron entre treinta minutos y dos horas. Se obtuvo el consentimiento informado de los entrevistados y el protocolo de investigación fue aprobado por la Comisión de Ética de Investigación Científica de la Facultad de Humanidades y Ciencias de la Educación de la Universidad de la República. Los nombres de los entrevistados fueron cambiados para preservar su identidad. Entendemos la entrevista como una relación social (43) a través de la cual se obtienen enunciados y verbalizaciones cuyo valor no está dado solo por el carácter referencial (información verdadera o falsa) sino también por su carácter performativo. La entrevista en profundidad, la no directiva o la etnográfica son las herramientas por excelencia para el acceso a las categorías "nativas" y a las representaciones discursivas $(41,43-45)$.

Como estrategia metodológica, se decidió comenzar el trabajo de campo con una etapa exploratoria, pautada por la observación participante e instancias de entrevistas informales, que permitieran la familiarización con el contexto y los códigos locales, y generar cierta empatía con los sujetos de estudio. Las entrevistas en profundidad se desarrollaron en una segunda etapa con el fin de focalizar y profundizar en el objeto de estudio.

A partir de la fase exploratoria inicial se pudo observar al menos tres tipos de vínculo entre los usuarios y la policlínica: a) personas con derechos asistenciales en la ASSE y que asistían esporádicamente a consultas espontáneas o programadas; b) personas que también tenían derechos asistenciales 
en la ASSE y que utilizaban el servicio de salud de manera frecuente, participando especialmente en espacios asistenciales colectivos; y c) personas que no tenían derechos asistenciales en la ASSE pero que aun así utilizaban algunos servicios asistenciales y/o participaban de actividades sociales vinculadas con la policlínica.

La selección de los usuarios para las entrevistas en profundidad consideró la heterogeneidad en género, edad, lugar de residencia y tipo de vínculo mantenido con el servicio de salud. La mayoría de las entrevistas fueron individuales.

Comenzamos nuestro trabajo indagando a los/as usuarios/as acerca de qué prácticas ponían en juego a la hora de enfrentar sus padecimientos cotidianos e intentamos comprender cómo esto se vinculaba con las concepciones que tenían sobre el proceso de salud-enfermedad-atención. Para ello, tomamos como punto de partida teórico y metodológico el análisis de los trayectos terapéuticos (7-10) y las experiencias del padecimiento (7).

En este trabajo nos centraremos en el análisis de las entrevistas informales realizadas a 20 usuarios/as, las entrevistas en profundidad realizadas a 25 usuarios/as y actores sociales vinculados al servicio de salud estudiado, y las diversas instancias de observación participante en espacios asistenciales y sociales.

\section{RESULTADOS}

Al indagar sobre los trayectos terapéuticos les preguntamos a las personas qué hacían cuando ellas o alguien de su familia estaban enfermas y en qué ocasiones recurrían a la policlínica estudiada. En sus primeras respuestas, afirmaban que no solían estar enfermas o nos contaban algún acontecimiento en el que ellas o alguien de su familia sufrieron un padecimiento "grave".

Las enfermedades o padecimientos que valían la pena ser contados en primer lugar eran los considerados "graves". La gravedad estaba asociada a alguna condición que hubiera puesto en riesgo la vida de la persona o requerido de una intervención médico-quirúrgica y/o de una internación prolongada en un hospital. Por otra parte, había una serie de malestares que no eran mencionados en un primer momento por los entrevistados. Al profundizar sobre este tema en los encuentros, reconocían que ciertos malestares y padecimientos de bajo umbral eran identificados como parte de la vida cotidiana, y que no se referían a ellos en primera instancia cuando eran consultados sobre sus trayectos de atención.

Por último, había una serie de motivos por los cuales recurrían al médico del barrio o a la policlínica: controles rutinarios de adultos, jóvenes y niños, consultas por "cuestiones de los niños", o, en algunos casos, un espacio de sociabilidad y encuentro.

A partir del análisis de las entrevistas, identificamos tres grandes categorías que los usuarios ponían en juego en relación con sus padecimientos y que ordenaban una serie de prácticas y sentidos a partir de los cuales podíamos analizar los trayectos terapéuticos recorridos.

\section{Malestares y padecimientos como parte del flujo "normal" de la vida}

Resfríos, gripes, dolores de barriga, dolores de garganta, heridas, quemaduras leves, entre otros malestares considerados "menores", no son mencionados cuando en las entrevistas se pregunta por enfermedades o malestares. Este es el tipo de padecimiento que se puede atender la mayoría de las veces "en casa", sin recurrir a ningún curador experto, y solo son mencionados por los entrevistados solo cuando se les pregunta si hay algún tipo de problema de salud que sea resuelto en casa.

Todas las personas que entrevistamos desarrollan prácticas para atender, controlar, curar y solucionar padecimientos en casa o sin la necesidad de consultar a un médico. Se combinan prácticas de atención que provienen de la biomedicina -como el uso de analgésicos- con prácticas de atención populares. Excepto en dos casos, los entrevistados preparaban tés e infusiones a base de plantas medicinales o "yuyos" como parte de las prácticas cotidianas:

Cuando se trata de gripe los atiendo yo nomás ¿viste? Si tienen fiebre y tengo remedio para la fiebre, si veo que la cosa no.. que tengan fiebre y no baja ni nada por el estilo, llamo enseguidita, y si no no, no son de vivir enfermos ni nada por el estilo, una 
simple gripe o algo, que uno sabe hacer los tés caseros que hacían los padres de uno y ta, hago eso y para el otro día están como rifle (risas) [...] Yo té, miel, pongo miel, azúcar quemada, limón, guaco, salvia... todos los yuyos que vea que sea para la gripe y encajo todo en el mismo té. Lo hiervo y se lo dejo enfriar y eso toma durante tres días. Lo hacía mi padre y mi madre todo cuando nosotros éramos chicos, con eso nos curábamos, no eran de llamar médico: gripe, bueno, a la cama y a tomar té. [Mujer, 29 años, usuaria esporádica]

La atención de malestares menores se realiza, en gran medida, a partir de la autoatención, que comprende:

\footnotetext{
...las representaciones y prácticas que la población utiliza a nivel de sujeto y grupo social para diagnosticar, explicar, atender, controlar, aliviar, aguantar, curar, solucionar o prevenir los procesos que afectan su salud en términos reales o imaginarios, sin la intervención central, directa e intencional de curadores profesionales, aun cuando estos pueden ser la referencia de la actividad de autoatención; de tal manera que la autoatención implica decidir la autoprescripción y el uso de un tratamiento en forma autónoma o relativamente autónoma. (46 p.198)
}

Las personas ponen en juego prácticas de autoatención de acuerdo con ciertos criterios diagnósticos, en los que la intensidad de los síntomas (principalmente, el dolor y la fiebre) y su duración son categorías centrales para evaluar la gravedad del padecimiento en cuestión. Una "simple gripe", un resfrío, una herida leve, son enfermedades que forman parte del flujo normal de la vida, producto del cambio de las estaciones o de accidentes domésticos cotidianos. Quienes Ilevan adelante los procesos de autoatención en el hogar son principalmente las mujeres: madres, esposas, abuelas, tías, hermanas mayores.

Existe otro tipo de padecimientos, propios de los bebés y niños pequeños, que requieren la intervención de curadores especializados no biomédicos: el empacho, el mal de ojo y la paletilla caída. Estos padecimientos se tratan mediante modos de atención del tipo tradicional o popular (46). En una entrevista, Patricia nos contó que ella siempre llevó a sus hijos a que le curaran el empacho, el mal de ojo y la paletilla caída con una señora a la que le dicen "la abuela". Llegó a consultarla a través de sus hermanas que también iban allí. "No sé, ella les pone la mano en la cabeza para curarle el mal de ojo y dice algo para adentro de ella, que nunca escuché lo que dijo, y la panza con un aceite que pasa en cruz y ta, así los cura". Cuando le pregunto si este tipo de terapia funciona, ella me explica que:

Sí, y si creés mejor todavía [...] porque si vos vas a una persona que no creés como que no te da resultado. $Y$ yo toda la vida mis hijos estaban empachados o algo, yo los llevaba y santo remedio, porque a veces no me dormían porque, viste, la panza les queda durita o algo, o hacen la caca muy fuerte o algo, ya ves, decís están empachados, los llevás, cuando querés ver duermen toda la noche tranquilos. [Mujer, 38 años, usuaria esporádica]

Patricia ya reconoce los síntomas del empacho y ante su aparición decide consultar directamente a "la abuela" y no al médico:

\begin{abstract}
No creo que un médico te vaya a sacar el mal de ojo, te va a decir no, no va a saber lo que tiene capaz y uno sabe que ellos tienen mal de ojo porque les duele la cabeza cuando tienen mal de ojo también, les duele la cabeza y duermen con los ojos abiertos. [Mujer, 38 años, usuaria esporádica]
\end{abstract}

Existirían una serie de malestares que son propios del campo de la medicina popular, para los cuales, desde la perspectiva de los sectores populares, el sistema biomédico no sería eficaz.

\section{Cuando se decide ir al médico: asistencia, sociabilidad y dificultades en el tránsito entre servicios}

Si la intensidad o duración del malestar supera lo considerado como un vaivén normal del flujo de la vida, o no es un malestar que pueda ser claramente identificado con la experticia de 
un curandero de la medicina popular (como en el caso del mal de ojo o del empacho), los usuarios entrevistados deciden "consultar al médico". Los síntomas como el dolor o la fiebre son los más mencionados a la hora de tomar esta decisión. A su vez, cuando deciden recurrir al saber biomédico, las personas eligen qué tipo de servicio de salud utilizarán. ¿En qué ocasiones se recurre al primer nivel de atención?, ¿cómo se transita entre los distintos niveles del sistema?, ¿existen otras puertas de entrada a los servicios de salud?

Luego de más de un año de trabajo de campo se observó que los usuarios esporádicos y los usuarios frecuentes asistían a la policlínica por consultas de control o por consultas denominadas "espontáneas". Los controles eran programados y agendados, ya fueran pediátricos, embarazos normales o adultos con algún padecimiento crónico. Los controles son estimulados por los servicios de salud o por otros organismos del Estado, en una lógica de salud y prevención. En el caso de niños, niñas y adolescentes está previsto que se realicen controles periódicos "en salud", los cuales son registrados en el Carné de Salud del Niño o en el Carné de Salud del Adolescente. Dichos carnés son exigidos y controlados tanto por las instituciones educativas (escuela y liceo) como para recibir beneficios de políticas sociales del Ministerio de Desarrollo Social.

Las consultas espontáneas se recibían el mismo día, por lo que, usualmente, el equipo de salud dejaba algún lugar libre en la agenda. Los motivos de consultas espontáneas que se observaron con mayor frecuencia estaban asociados a malestares en niños o en mujeres como, por ejemplo, gripes y resfríos, infecciones respiratorias, gastroenterocolitis, etc., con síntomas como dolor, malestar, o fiebre.

En el caso de los usuarios frecuentes, otro motivo de utilización de la policlínica eran los espacios de asistencia colectivos: el Espacio Adolescente en el caso de los jóvenes, y el grupo de adultos que estuvieran diagnosticados como obesos y/o diabéticos y/o hipertensos (ODH). El sentido dado a estos espacios trasciende lo asistencial-curativo y refiere a la sociabilidad. En el caso del grupo $\mathrm{ODH}$ no solo se comparten las experiencias de padecimiento sino también se conocen nuevas personas, se intercambia sobre la vida cotidiana:

\begin{abstract}
...las charlas son muy agradables, te enseñan cómo llevar la enfermedad, cómo tratarte, cómo comportarte, cómo te tenés que alimentar [...] Hacen juegos también. Pero no, no, la verdad. Ah, y jla parte de la integración! No es solo hablar de la enfermedad sino también la integración de todo un grupo de personas que no nos conocíamos y que nos conocimos en ese momento. [Hombre, 65 años, usuario frecuente, participa del grupo $\mathrm{ODH}]$
\end{abstract}

En el caso del Espacio Adolescente las actividades desarrolladas se centraban en el juego y la discusión de temas de interés. Los jóvenes Ilevaban música, jugaban al ping-pong o al voleibol en un espacio verde que pertenece al predio de la policlínica, organizaban actividades para juntar fondos para un campamento de fin de año, entre otras tareas:

En el espacio nos divertimos mucho, hacemos a veces actividades, hablamos de temas que nos interesan a todos, hacemos actividades para poder recaudar dinero para salir algún lado entre todos. Tenemos una página de Facebook que nos comunicamos entre todos para contarnos algunas novedades de la policlínica. Ahora estamos tramitando la tarjeta joven [...] Como que somos todos amigos, es fuera ya de lo laboral de las doctoras. Fuera del trabajo de ellas, es más personal, está buenísimo. [Mujer, 15 años, usuaria frecuente, participante del Espacio Adolescente]

Por último, identificamos personas que si bien no se atendían en la policlínica, participaban de actividades organizadas allí como, por ejemplo, asambleas de usuarios, actividades comunitarias de promoción de la salud, actividades recreativas que también eran entendidas como espacios de sociabilidad.

Si bien todas las personas entrevistadas valoraban la atención de la policlínica estudiada como buena o muy buena, y destacaban especialmente la calidez de la relación con los distintos profesionales, identificaban problemas cuando era necesario coordinar alguna actividad asistencial (estudios paraclínicos, interconsultas) con el centro de salud o con algún otro servicio del 
segundo o tercer nivel. Las dificultades experimentadas por los usuarios para acceder a un estudio (exámenes de orina, sangre, ecografías) en tiempo y forma, o para concretar una consulta con un especialista, son narradas en diferentes entrevistas. Los principales problemas descritos son largos tiempos de espera para acceder a los especialistas, y problemas y extravíos en la coordinación de estudios.

Como se mencionó en el apartado anterior, las personas evalúan la "gravedad" del padecimiento a partir de criterios diagnósticos y de los criterios del sistema de autoatención (46) para decidir, en primer lugar, si consultar a un servicio de salud biomédico o no. Si se decide consultar, estos mismos criterios orientan la elección de cuál servicio utilizar:

La emergencia que utilizo es la del Pasteur

(b). Porque como ya te hacen una placa, una ecografía, algo urgente te lo hacen ahí. Si voy a Libia (c) es para que después te deriven al Pasteur entonces ya voy directo al Pasteur. [Mujer, 68 años, usuaria esporádica]

En nuestra investigación identificamos que los usuarios no siempre recurren a un servicio del primer nivel de atención como "puerta de entrada al sistema" como se prevé que suceda desde la gestión sino que, en algunos casos, prefieren ir directamente a una puerta de emergencia de un servicio del segundo o tercer nivel, sorteando los mecanismos institucionales previstos y de esta forma acceder a estudios paraclínicos de forma más rápida. Los testimonios que recogimos sugieren que, si bien en algunos casos la consulta en el segundo nivel resultaba pertinente, en otros casos se recargaba el segundo nivel con situaciones que podrían ser resueltas desde el primero si las coordinaciones se realizaran en tiempo y forma.

\section{Experiencias de enfermedad significativas: "Hay uno enfermo y sacude a toda la familia"}

Mientras que en un extremo encontramos malestares que son considerados parte del flujo normal de la vida o que son mencionados de manera casual, hay otros malestares y experiencias de enfermedad que resultan significativas tanto para el sujeto como para su grupo cercano. En sus relatos, los entrevistados que se refirieron a estas experiencias de enfermedad significativas ofrecían insights sobre diferentes dimensiones de la sociabilidad como, por ejemplo, las relaciones de amistad y parentesco, sobre el paso del tiempo, o sobre las condiciones sociales y económicas de vida, evidenciando que en estos casos la experiencia de padecimiento es profundamente social (7).

En las narrativas sobre la enfermedad se elabora y expresa la relación entre el sujeto y el contexto, percibida como fundamento de la experiencia de padecimiento (47). Nos acercaremos a la experiencia de enfermedad de Gabriela (usuaria esporádica, 37 años) y su familia. Gabriela vive a unas pocas cuadras de la policlínica estudiada. Tiene tres hijos y convive con Ricardo. Ella se dedica al cuidado del hogar y de sus hijos. Ha trabajado de manera intermitente limpiando en casas de familias de clase media alta. Gabriela y sus hijos utilizan la policlínica desde su creación, además ha utilizado diversos servicios de salud de la ASSE siguiendo el trayecto terapéutico de sus hijos Emilia y Joao. Durante los estudios e internaciones que atravesaron sus hijos, destaca el apoyo de su familia, especialmente la presencia de su hermana y su madre. En ocasión de un estudio para evaluar el canal deglutor, la niña sufrió una neumonía química a causa de una mala maniobra del personal de salud:

\footnotetext{
Desde que tenía 30 días empezó con el reflujo. Le mandaron a hacer estudios y todo. Y cuando tenía tres meses fue que cayó internada porque le hicieron el estudio ese para ver lo del reflujo y se le aspiró el medicamento para los pulmones. Ahí fue la primera vez que me fue a parar para internar. Que estuvo un montón de días. Como doce días estuvo. Yo no me desprendí de ella. Mamá y Valeria iban para que yo pudiera venir a descansar y yo no me desprendí de ella. Me quedaba en un sillón al lado de la cuna. Ahí me decían que me iba a terminar enfermando porque yo no me quería dormir viste. [Mujer, 37 años, usuaria esporádica]
}

Joao, también tenía problemas de salud graves, pero a diferencia de Emilia, no lograban un diagnóstico médico: 
Joao pasó internado, internado, internado. Le hicieron de todo, vieron médico dos por tres y de todo le hacían porque no sabían qué tenía. Se pasaba haciendo episodios de fiebre altísima, lo tenían internado, le hicieron de todo y no daban con lo que era. Y lo terminamos llevando a un hombre. Porque a veces hay que creer o reventar. [...] Ta, el hombre estuvo con él ahí. Le hizo unos "saravás" (d). No se, el hombre le hablaba. No entendíamos lo que decía. Le dice, ahora comprá una coca bien frío y dásela. Ta, se la dimos. Al otro día en el patio jugando a la pelota. Míralo cómo está. Joao no tuvo más nada. Después de eso... le hicieron una tomografía me acuerdo, después de eso, porque ya tenía la fecha. Nada. Después ta. Los médicos me dijeron "Ta, no tiene nada el niño. No le vamos a decir que tiene porque no tiene". [Mujer, 37 años, usuaria esporádica]

Ante la enfermedad de su hijo, Gabriela y su marido recurrieron en primer lugar al sistema biomédico. Luego de múltiples estudios, internaciones y recaídas y ante la ausencia de una explicación de las causas de la enfermedad de su hijo decidieron recurrir a un curador popular. Gabriela postergó el cuidado de su salud en pos de sus hijos, faltando a consultas previstas u omitiendo la realización de controles previstos, tanto por "dejarse estar" como por miedo de los posibles resultados:

\footnotetext{
Me levanté un día que me iba. Se me iba la cabeza, me iba de costado, horrible. Todo por el estrés porque andaba con Emilia viste, porque andaba muy nerviosa, se me había juntado todo. $Y$ me mandó una medicación que me ayudó un montón. Ya me saturó tanto con Emilia que no quiero ver más médico, no quiero ver más nada. $Y$ además pienso, si caigo internada yo, me mandan alguna cosa o algo ¿qué hago con los gurises? [Mujer, 37 años, usuaria esporádica]
}

El estrés atravesado, las horas de hospital, las andanzas, la odisea que ha significado para Gabriela y su familia la enfermedad de sus hijos habían afectado sus "nervios". Los nervios se han estudiado en diversos contextos socioculturales en la antropología médica. Según Alves y Rabelo (47), se trata de una categoría polisémica característica de un modo de pensar la persona. Estos autores afirman que en los relatos autobiográficos de mujeres nerviosas en Brasil, el estado nervioso aparece como una reacción inadecuada o desproporcionada al contexto. Esa reacción generalmente es atribuida a una situación de pobreza y privaciones que imponen serios límites a la posibilidad de conducir la vida con tranquilidad, maximizados por un contexto cotidiano de violencia y falta de autodeterminación, como la imposibilidad de sostener una identidad personal y una red con otros que sostengan esa identidad (47). En el caso de Gabriela, ella no se define a sí misma ni es definida por otros como una persona nerviosa, sino que en un determinado momento estuvo nerviosa, a lo cual atribuye sus problemas de vértigo. Su red con otros, especialmente su familia nuclear de origen, es fuerte y la ha ayudado a afrontar y sostener las diferentes dificultades a las que se ha afrontado:

\begin{abstract}
[La enfermedad] nos ha tocado tanto. Porque hay uno enfermo y sacude toda la familia. Porque es la verdad. Con lo de Emilia han estado todos conmigo, todos conmigo. Y está uno enfermo y está toda la familia mal. Porque es así. Nos preocupamos todos. Te dicen puede ser esto, puede ser aquello. Cuando hay uno enfermo es bravo. Es bravo eso, es bravo monetariamente. En el caso de mi marido cuando estuvo con tendinitis nos vinimos abajo. Mal. Nos tapamos de cuentas. [Mujer, 37 años, usuaria esporádica]
\end{abstract}

No trabajar acarrea problemas financieros inmediatos ya que, en este caso, afecta sobre todo al proveedor de la casa. En el caso de las mujeres, la enfermedad no solo interrumpe el empleo formal, en caso de que lo hubiere, sino que también interrumpe el trabajo doméstico, tanto las tareas domésticas como el cuidado de los niños.

Las relaciones de parentesco y el contexto social, cultural, religioso y económico están profundamente entrelazados con las diversas experiencias de enfermedad que transitaron Gabriela y su familia. Como han indicado numerosos antecedentes de la antropología médica, la experiencia de la enfermedad es profundamente social. 


\section{DISCUSIÓN}

Como hemos venido desarrollando a lo largo de este trabajo, las personas elaboran construcciones e interpretaciones a partir de su experiencia del proceso salud-enfermedad-atención. Cuando indagamos con los/las usuarios/as de la policlínica estudiada qué prácticas y sentidos despliegan ante sus malestares y padecimientos, encontramos que es posible agrupar algunos trayectos terapéuticos dependiendo de cómo son clasificados y ordenados los malestares y padecimientos así como los recursos terapéuticos a los que se recurre.

Los análisis de Veena Das et al. (7) en una investigación sobre la experiencia de malestar subjetiva entre personas pobres de Nueva Delhi nos sirvieron como referencia analítica para interpretar los sentidos emergentes en nuestra investigación. La diversidad de contextos en los que los participantes experimentaban los malestares variaba desde un extremo del espectro, en el que eran fácilmente absorbidos como parte del flujo normal de la vida, a otro, en el que las historias de la enfermedad estaban perseguidas por el sentido de la falla del cuerpo y de las relaciones sociales.

En nuestro caso, encontramos una serie de malestares y padecimientos que eran clasificados como parte del flujo "normal" de la vida y para los cuales se recurría a prácticas terapéuticas de autoatención y/o se recurría a curadores populares. Según Menéndez, la autoatención es la forma de atención de la enfermedad más frecuente utilizada por los grupos sociales y sintetizadora de las otras formas de atención, de forma constante (aunque intermitente) y autónoma (46). Las principales encargadas de llevar adelante los procesos de autoatención eran las mujeres del hogar (principalmente madres, tías y/o abuelas). Esto coincide con lo señalado en la bibliografía $(48,49)$ que identifica a la mujer como vehículo de cura, en tanto es la que generalmente maneja los remedios, la alimentación y la que decide si verdaderamente hay enfermedad o no.

En segundo lugar, identificamos una serie de prácticas y sentidos asociados al uso de servicios de salud del primer nivel de atención, así como una serie de dificultades relativas a la circulación al interior de dicho nivel de atención y desde este hacia otros niveles del sistema de atención biomédico.
La policlínica estudiada era vista por los usuarios esporádicos como un espacio asistencial, destinada a controles rutinarios de adultos, jóvenes y niños y a consultas por malestares principalmente infantiles; y, por los usuarios frecuentes, como un espacio asistencial y de sociabilidad. Los trabajos sobre grupos centrados en padecimientos (el caso paradigmático es el de Alcohólicos Anónimos), nos orienta en la comprensión de grupos como el de ODH o el Espacio Adolescente, para cuyos usuarios la policlínica se constituía en un espacio de relacionamiento social más allá de la función asistencial. Un aspecto importante en este tipo de grupos es la búsqueda de relaciones sociales entre los miembros (50). Si bien el grupo se forma en torno a un conjunto de padecimientos que son los que le dan identidad al grupo como tal, los integrantes del grupo también comparten otros elementos de pertenencia social y de referencias culturales comunes que permiten que el espacio trascienda lo asistencial y opere como un espacio necesario de pertenencia y sociabilidad. En el caso de los participantes del grupo $\mathrm{ODH}$, esto es especialmente significativo ya que la oferta de espacios recreativos o culturales para los adultos mayores, en esa zona, es escasa o inexistentes. En el caso del Espacio Adolescente, el grupo no se organiza en torno a un padecimiento sino a una franja etárea que es considerada "prioritaria" desde las políticas nacionales de salud. $\mathrm{Ni}$ en el barrio donde se ubica la policlínica ni en zonas cercanas existen plazas, parques u otro tipo de espacio público, lo cual incidiría en que la policlínica y el salón comunal donde se desarrolla el Espacio Adolescente se hayan convertido en un espacio de referencia para algunos jóvenes del barrio.

En relación con las dificultades de circulación al interior del primer nivel de atención y desde este hacia otros niveles del sistema, identificamos que los usuarios utilizan diferentes estrategias para poder lograr la mejor solución a sus problemas de salud en el menor tiempo posible. En algunos casos, toman la opción de entrar al sistema de salud por la "puerta de emergencia" de los hospitales o centros de salud, ya que allí les resulta más fácil acceder a estudios paraclínicos. En datos publicados por el Ministerio de Salud Pública se establece que la razón entre las consultas realizadas en policlínicas sobre las consultas urgentes 
centralizadas para la ASSE es de 2,9, mientras que el promedio para el país es de 6,2.

[El] indicador: razón [consultas policlínica] / [consultas urgentes centralizadas] [...] refleja la relación entre las consultas ambulatorias de policlínicas y las consultas urgentes centralizadas, es decir las efectuadas a nivel del Servicio de Urgencia - Emergencia Institucional, realizadas en el último año (desde octubre de 2012 hasta setiembre de 2013). El número de consultas realizadas en cada ámbito son informadas al MSP por las instituciones mensualmente. (51 p.7)

Este dato apoya la hipótesis de que las personas recurren con mayor frecuencia de la esperada a la atención en "puertas de emergencia". Si bien se necesitan más investigaciones para comprender el fenómeno con mayor profundidad, que los usuarios decidan ingresar al sistema de salud por la puerta de emergencia de hospitales y no desde el primer nivel puede ser un indicio de fragmentación del sistema. Según la Organización Panamericana de la Salud:

En el desempeño general del sistema, la fragmentación se manifiesta como falta de coordinación entre los distintos niveles y sitios de atención, duplicación de los servicios y la infraestructura, capacidad instalada ociosa y servicios de salud prestados en el sitio menos apropiado, en especial, en los hospitales. Algunos ejemplos concretos incluyen la baja capacidad de resolución del primer nivel de atención, el uso de servicios de urgencia para tener acceso a la atención especializada, con lo cual se elude la consulta ambulatoria, la admisión de pacientes a los hospitales cuyos casos podrían haberse resuelto en forma ambulatoria o la prolongación de la estadía en los hospitales por dificultades para dar de alta a los enfermos con problemas sociales. (39 p.21)

Por último, encontramos que una serie de padecimientos eran clasificados como experiencias de enfermedad significativas. Ante este tipo de padecimientos, los trayectos terapéuticos recorridos podían combinar el tránsito por servicios de distintos niveles de atención del sistema biomédico y otros sistemas de atención (populares, religiosos, new age). Asimismo, ante las experiencias significativas de enfermedad, el sistema de relaciones sociales del enfermo y su entorno cobra especial relevancia. ¿Qué personas acompañaban en el proceso?, ¿cómo se veían afectados aspectos de la vida cotidiana tales como la gestión del hogar, el cuidado de los niños y el trabajo durante el transcurso del padecimiento en cuestión? Como observan Das et al.:

...las historias de las enfermedades en muchos casos eran también las historias de las relaciones de parentesco, de quién había ayudado y quién había traicionado; los entrevistados describían a menudo cómo el episodio de ese momento se relacionaba con episodios de enfermedad anteriores, o reflexionaban sobre las condiciones sociales y económicas en las que ellos vivían. La enfermedad en sentido amplio es profundamente social. (7) [traducción personal]

Observamos que, tanto ante malestares que son considerados como parte del flujo natural de la vida como ante experiencias de enfermedad significativas, las personas recurren a un conjunto de formas de atención y actividades de autoatención que articulan de la mejor manera posible para solucionar sus padecimientos. Esta observación coincide con diferentes investigaciones realizadas en América Latina (46), en India (7) y en China (11), en las que se analiza cómo los sujetos y grupos sociales emplean diferentes estrategias a la hora de enfrentarse a un padecimiento y pueden utilizar diferentes formas de atención en un contexto determinado.

Referirse desde un punto de vista antropológico a las formas de atención no implica necesariamente reconocer su eficacia y/o eficiencia sino reconocer su existencia.

Lo que domina en las sociedades actuales, dentro de los diferentes conjuntos sociales estratificados que las constituyen y más allá de la situación de clase o de la situación étnica, es lo que se conoce como pluralismo médico, término que refiere a que en nuestras sociedades la mayoría de la población utiliza potencialmente varias formas de atención no 
sólo para diferentes problemas, sino para un mismo problema de salud. (46 p.186)

Esta integración de diferentes modos de atención también podría estar respondiendo a una concepción holista de los procesos de salud y enfermedad y que por tanto procura también respuestas plurales para su atención.

\section{CONCLUSIONES}

En este trabajo nos propusimos indagar las prácticas y sentidos que se ponen en juego ante diferentes padecimientos que las personas deben afrontar en la vida cotidiana y cómo se relacionan con el uso de servicios de primer nivel de atención.

Encontramos que existen una serie de malestares y padecimientos que son clasificados como parte del flujo "normal" de la vida y ante los cuales se recurre a prácticas terapéuticas de autoatención y/o a curadores populares. Se trata de malestares que pueden ser considerados como parte de la vida cotidiana y que no son representados como una enfermedad en sí misma (por ejemplo, la cura del mal de ojo, la paletilla caída o el empacho) y para los cuales no se requiere el uso de la policlínica (servicios de salud del primer nivel de atención) ni de otros servicios de salud del sistema de atención biomédico.

En segundo lugar, encontramos que la policlínica es utilizada y concebida como un espacio asistencial y como un espacio de sociabilidad. El servicio de salud estaría destinado a controles rutinarios de adultos, jóvenes y niños y a consultas por malestares principalmente infantiles cuyos síntomas superan el umbral de los que son considerados como parte del flujo normal de la vida. En este nivel, la atención es valorada muy positivamente. Sin embargo, cuando es necesario coordinar con algún otro servicio de salud aún

\section{NOTAS FINALES}

a. El presente artículo se enmarca en un estudio más amplio desarrollado en el marco de la Maestría en Ciencias Humanas, opción Antropología de la no existe una adecuada integración entre los diferentes niveles del sistema de atención ni entre diferentes servicios del primer nivel. Se refirieron problemas tanto a nivel de la gestión (demoras, extravíos, errores) como falta de los recursos necesarios para resolver las situaciones asistenciales en el nivel correspondiente. Ante estas situaciones se sugiere que podría haber una tendencia de los usuarios a adoptar la estrategia de entrar al sistema de salud mediante las "puertas de emergencia" y no mediante el primer nivel como está previsto. Esto evidencia cierta fragmentación en el sistema de salud que conlleva consecuencias no deseadas. Entre los usuarios frecuentes de la policlínica encontramos que se comparten otros elementos de pertenencia social y referencias culturales comunes que permiten que el espacio trascienda lo asistencial y opere como un necesario espacio de pertenencia y sociabilidad.

Por último, encontramos que algunos padecimientos eran clasificados como experiencias de enfermedad significativas. Ante este tipo de experiencias, las relaciones sociales de los sujetos cobraban gran relevancia y los trayectos terapéuticos recorridos podían combinar el tránsito por servicios de distintos niveles de atención del sistema biomédico y otros sistemas de atención (popular, religiosos, new age).

Desde un punto de vista antropológico no nos interesó indagar sobre el éxito de las diferentes prácticas de atención, sino reconocer su existencia ya que los usuarios recurren a estas ante diferentes situaciones de su proceso de salud-enfermedadatención. El uso de otros sistemas de atención no es excluyente respecto de la utilización del sistema biomédico, por el contrario, las personas combinan los diferentes sistemas y deciden cuál es el más adecuado ante cada situación de acuerdo con sus representaciones sociales de la salud y la enfermedad. Esta integración de sistemas de atención y prácticas de autoatención coincide con el pluralismo médico identificado en los sectores populares de otros países de América Latina. 
atención. Etnografía en una policlínica del Primer Nivel de Atención dependiente del Centro de Salud de Jardines del Hipódromo, ASSE."

b. Refiere al Hospital Pasteur, dependiente de la Administración de los Servicios de Salud del Estado. c. Refiere a la puerta de emergencia del Centro de Salud Jardines del Hipódromo, ubicado sobre la calle Libia.

d. Término relacionado con un saludo religioso y/o buenos augurios en religiones afrobrasileñas.

\section{AGRADECIMIENTOS}

A los usuarios y trabajadores de la policlínica estudiada por permitirme desarrollar la presente investigación con ellos. Al equipo de gestión del Centro de Salud Jardines del Hipódromo y a la sub dirección de la Red de Atención Primaria Metropolitana de la Administración de los Servicios de Salud del Estado (RAP-ASSE) por otorgarme las autorizaciones institucionales necesarias. A la Agencia Nacional de Investigación e Innovación (ANII) por la Beca de Posgrados Nacionales de Maestría que me permitió realizar la Maestría en Ciencias Humanas, Opción Antropología de la Cuenca del Plata, de la Facultad de Humanidades y Ciencias de la Educación, Universidad de la República, Uruguay.

\section{REFERENCIAS BIBLIOGRÁFICAS}

1. Moreno Altamirano L. Reflexiones sobre el trayecto salud-padecimiento-enfermedad-atención: una mirada socioantropológica. Salud Pública de México. 2008;49(1):63-70.

2. Pizza G. Antropología médica: una propuesta de investigación. En: Lizón C, editor. Introducción a la antropología social y cultural. Madrid: Akal; 2006. p. 267-291.

3. Martínez Hernáez A. Antropología médica: teorías sobre la cultura, el poder y la enfermedad. Barcelona: Anthropos; 2008.

4. Ember C, Ember M. Encyclopedia of medical anthropology: Health and illness in the world's cultures. New York: Springer; 2004.

5. Díaz Duarte F. Pessoa e dor no occidente. Horizontes Antropológicos. 1998;(4):13-28.

6. Laplantine F. Antropología de la enfermedad: Estudio etnológico de los sistemas de representaciones etiológicas y terapéuticas en la sociedad occidental contemporánea. Buenos Aires: Ediciones del Sol; 1999.

7. Das V, Das R. How the body speaks: Illness and the lifeworld among the urban poor. En: Biehl J, Good BA, editors. Subjectivity: Ethnographic investigations. London: University of California Press; 2007.

8. Menéndez E. De sujetos, saberes y estructuras: Introducción al enfoque relacional en el estudio de la salud colectiva. Buenos Aires: Lugar Editorial; 2009.

9. Goffman E. Estigma-Notas sobre a manipulação da identidade deteriorada. Río de Janeiro: Zahar; 1980.

10. Goffman E. Internados: ensayo sobre la situación social de los enfermos mentales. Buenos Aires: Amorrortu; 2001.

11. Kleinman A. Patients and healers in the context of culture: An exploration of the borderland between anthropology, medicine, and psychiatry (vol. 3). Los Angeles: University of California Press; 1980.

12. Kleinman A. Local worlds of suffering: An interpersonal focus for ethnographies of illness experience. Qualitative Health Research. 1992;2(2):127-134.

13. Kleinman A, Benson P. Anthropology in the clinic: The problem of cultural competency and how to fix it. PLoS Medicine. 2006;3(10):291-294.

14. Menéndez EL. El modelo médico y la salud de los trabajadores. Salud Colectiva. 2005;1(1):9-32.

15. Barber N, Margulis S. Procesos de atención de personas que viven con $\mathrm{VIH}$ : Un enfoque desde las trayectorias terapéuticas. En: Grimberg $M$, editora. Experiencias y narrativas de padecimientos cotidianos: Miradas antropológicas sobre la salud, la enfermedad y el dolor crónico. Buenos Aires: Antropofagia; 2009. 
16. República Oriental del Uruguay. Ley 18.211, Sistema Nacional Integrado de Salud. Normativa referente a su creación, funcionamiento y financiación [Internet]. Montevideo: 21 nov 2007 [citado 15 sep 2014]. Disponible en: http://goo. $\mathrm{gl} / 6$ yop $2 \mathrm{~W}$.

17. Organización Mundial de la Salud. Informe sobre la salud en el mundo 2008: La atención primaria de salud, más necesaria que nunca. Ginebra: OMS; 2008.

18. Romero S. Transformaciones en el campo de la salud en el Uruguay: ¿una revolución cultural? En: Barrán JP. La medicalización de la sociedad. Montevideo: Nordan Comunidad; 1993.

19. Alvarez Pedrosian E. Los estrategas del Maciel: etnografía de un hospital público. Montevideo: Universidad de la República, CSIC; 2009.

20. Mesa S, Viera M. Tramas de significado y negociación de poder en la consulta ginecológica. Trabajo presentado en: VII Congreso Argentino de Antropología Social; 2004; Villa Giardino, Córdoba.

21. Rostagnol S, Viera M. Derechos sexuales y reproductivos: condiciones habilitantes y sujetos morales en los servicios de salud: Estudio en el Centro Hospitalario Pereira Rossell, Uruguay. En: Checa S, comp. Realidades y coyunturas del aborto: entre el derecho y la necesidad. Buenos Aires: Paidós; 2006

22. Vomero F. Enfermedad mental, psiquiatría y cultura en el Uruguay de la primera mitad del siglo XX. [Tesis de Maestría]. Montevideo: FHCEUDELAR; 2010.

23. Evia V. Porque necesito de voz para poner mi voz al aire... Etnografía en Radio Vilardevoz: representaciones sociales sobre la locura y prácticas de resistencia [Tesina de Grado]. Montevideo: Facultad de Humanidades y Ciencias de la Educación, Universidad de la República; 2010.

24. Wainwright M. Faltar el aire: enfermedad pulmonar obstructiva crónica en Uruguay. Anuario de Antropología Social y Cultural en Uruguay. 2013;II:275-278.

25. Romero S. Madres e hijos en la Ciudad Vieja. Montevideo: Nordan; 2003.

26. Menoni AC, Evia V, Apud I. Inclusión social y salud mental: reflexiones sobre las condiciones de accesibilidad a los servicios de salud mental descentralizados de Montevideo a partir de un estudio de caso. Psicología, Conocimiento y Sociedad. 2003;3(1):41-63.
27. Romero S. La diversidad en el campo de la salud. Anuario de Antropología Social y Cultural en Uruguay. 2004-2005:111-120.

28. Romero S. Modelos culturales y sistemas de atención de la salud. Anuario de Antropología Social Cultural en Uruguay. 2006:205-209.

29. Romero S. Dossier: Veinte años de estudios en antropología y salud en Uruguay. Cuadernos del CES No5. 2009;(5):31-33.

30. Romero S. Relaciones conflictivas entre usuarios y profesionales de la salud. Estudio de caso en base a hechos acaecidos en la ciudad de Salto entre diciembre 2008 y enero 2009. Anuario Antropología Social y Cultural en Uruguay. 2009-2010:151-164.

31. Romero S. Integración de paradigmas médicos, innovaciones en la atención de la salud: Proyección al siglo XXI. Anuario de Antropología Social y Cultural en Uruguay. 2013;11:197-209.

32. Instituto Nacional de Estadística. Microdatos: Encuesta Continua de Hogares 2012 [Internet]. 2013 [citado 15 sep 2014]. Disponible en: http:// goo.gl/2vrjPi.

33. Grau C, Lazarov L, Mieres G, Olivera I, Rodríguez $\mathrm{H}$. Informe final de la consultoría sobre Salud en el marco del Plan Estratégico Nacional en Ciencia, Tecnología e Innovación. Montevideo: ANII; 2008.

34. Instituto Nacional de Estadística. Principales resultados de la Encuesta Continua de Hogares 2011 [Internet]. Montevideo: INE; 2011 [citado 15 sep 2014]. Disponible en: http://goo.gl/6KvU1Z.

35. Olesker D, González T. La construcción del Sistema Nacional Integrado de Salud (2005-2009). Montevideo: Ministerio de Salud Pública; 2009.

36. Vignolo J, Vacarezza M, Sosa A. Niveles de atención, de prevención y atención primaria de la salud. Archivos de Medicina Interna. 2011;XXXIII (1):11-14.

37. Organización Panamericana de la Salud. Redes Integradas de Servicios de Salud: Conceptos, opciones de política y hoja de ruta para su implementación en las Américas. Washington DC: OPS; 2010.

38. Administración de los Servicios de Salud del Estado. Red de Atención del Primer Nivel [Internet]. Montevideo: ASSE [citado 15 sep 2014]. Disponible en: http://goo.gl/xtZ1rW.

39. Administración de los Servicios de Salud del Estado, Dirección de Sistemas de Información, 
Departamento de Gestión de la Información. Total del país de usuarios ASSE por tipo de cobertura según sexo y grupos de edad [Internet]. 2013 [citado 15 sep 2014]. Disponible en: http://goo.gl/ $\mathrm{EGq} 2 \mathrm{GH}$.

40. Ghasarian C. Por los caminos de la antropología reflexiva. En: Ghasarian C, comp. De la etnografía a la antropología reflexiva: nuevos campos, nuevas prácticas, nuevas apuestas. Buenos Aires: Del Sol; 2008.

41. Guber R. La etnografía: Método, campo y reflexividad. Buenos Aires: Siglo XXI Editores; 2011.

42. Evia V. Representaciones sociales, estrategias y experiencias de usuarios y trabajadores de la salud en los procesos de salud-enfermedad-atención: Etnografía en una policlínica del Primer Nivel de Atención dependiente del Centro de Salud de Jardines del Hipódromo, ASSE. Montevideo: CSE, FHCE; 2014.

43. Bourdieu P. La miseria del mundo. Buenos Aires: Fondo de Cultura Económica; 1999.

44. Blanchet A. Entrevistar: Técnicas de investigación en Ciencias Sociales. Madrid: Narcea; 1989.

45. Delgado JM, Gutiérrez J. Métodos y técnicas cualitativas de investigación en Ciencias Sociales. Madrid: Síntesis; 1995.
46. Menéndez E. Modelos de atención de los padecimientos: de exclusiones teóricas y articulaciones prácticas. Ciência \& Saúde Coletiva. 2003;8(1):185-207.

47. Alves P, Rabelo M. Nervios, proyectos e identidades: narrativas de la experiencia. En: Grimberg $M$, editora. Experiencias y narrativas de padecimientos cotidianos: Miradas antropológicas sobre la salud, la enfermedad y el dolor crónico. Buenos Aires: Antropofagia; 2009.

48. Menéndez E. Introducción. En: Spinelli H, Menéndez $\mathrm{E}$, coords. Participación social ¿Para qué? Buenos Aires: Lugar Editorial; 2008.

49. Fitzpatrick R, Hinton J, Newman S, Scambles G, Thompson J. La enfermedad como experiencia. México: Fondo de Cultura Económica; 1990.

50. Menéndez E. Las múltiples trayectorias de la participación social. En: Spinelli H, Menéndez E, coords. Participación social ¿Para qué? Buenos Aires: Lugar Editorial; 2008.

51. Ministerio de Salud Pública. Movilidad regulada de los usuarios del Seguro Nacional de Salud-Fonasa [Internet]. 2014 [citado 15 sep 2014]. Disponible en: http://goo.gl/kKEJD6.

FORMA DE CITAR

Evia Bertullo V. Los procesos de salud-enfermedad-atención desde la perspectiva de los usuarios de una policlínica del primer nivel de atención en Montevideo, Uruguay: Análisis de trayectos terapéuticos. Salud Colectiva. 2015;11(4):537-552.

Recibido: 21 de octubre de 2014 | Versión final: 17 de abril de 2015 | Aprobado: 29 de mayo de 2015

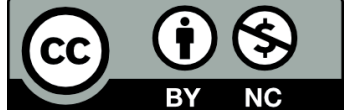

Este obra está bajo una licencia de Creative Commons Reconocimiento-NoComercial 4.0 Internacional. Reconocimiento - Permite copiar, distribuir y comunicar públicamente la obra. A cambio, se debe reconocer y citar al autor original. No Comercial - Esta obra no puede ser utilizada con finalidades comerciales, a menos que se obtenga el permiso.

http://dx.doi.org/10.18294/sc.2015.794 